\title{
Evaluation of the in vitro Antiprotozoal Activity of Various Dry Plant Extracts against Dientamoeba fragilis
}

\section{Joel Barratt ${ }^{1,3}$, John Ellis ${ }^{1,3}$, John Harkness ${ }^{2,3}$, Deborah Marriott ${ }^{2,3}$ and Damien Stark ${ }^{2,3 *}$}

${ }^{1}$ iThree Institute, University of Technology, Sydney, Broadway, Australia

${ }^{2}$ Division of Microbiology, SydPath, St. Vincent's Hospital, Darlinghurst, Australia

${ }^{3}$ School of Medical and Molecular Biosciences, University of Technology, Sydney, Broadway, Australia

Plants represent an important source of diverse biomolecules with unique properties, some of which make them attractive candidates for the development of novel antimicrobials. Plant extracts have been evaluated in vitro for their activity against human-infecting gastrointestinal protozoa, such as Giardia intestinalis [1] and Entamoeba histolytica [2], with some success. Some plant extracts are also active against the sexually transmitted parasite Trichomonas vaginalis [2].

For the treatment of infections with microaerophilic protozoa, such as Dientamoeba fragilis and G. intestinalis, metronidazole (Flagyl ${ }^{\circ}$ has been the drug of choice for decades. However, it is well established that the widespread use of monotherapeutic treatment regimens encourages drug resistance, leading to treatment failures and relapses of illness. Recently, resistance to Flagyl has been observed in T. vaginalis [3] and G. intestinalis [4], and has been suggested in the bowel parasite; $D$. fragilis, due to the increasing frequency of treatment failures [5]. With the emergence of drug resistance, there is increasing pressure to identify new drugs. In response to reports of possible Flagyl resistance in $D$. fragilis [5], a simple study was designed to determine whether non-prescription dry plant extracts commercially available from local health stores exhibit direct anti-Dientamoeba activity.

Dry plant extracts were selected based on reports of their antibacterial, antiprotozoal, and/or anthelmitic activity. The agents were also selected, as they are prescribed by many alternate health practioners as effective treatment for dientamoebiasis. The products evaluated included pomegranate (Punica granatum) peel extract, Garlic (Allium sativa) extract (crushed tablets), Goldenseal (Hydrastis candensis) extract (crushed tablets), Black Walnut (Juglans nigra) extract (crushed tablets), Wormwood (products from two species; Artemesia annua and Artemisis absinthium) each in crushed tablet form, Wormseed (Chenopodium ambrosioides) extract (crushed tablets), Pumpkin seeds (Cucurbita sp.) ground to fine powder, Grapefruit seed extract (powdered) and Ginger root extract (powdered).

Four clinical isolates of $D$. fragilis were used in this study. Dientamoeba trophozoites were cultured in a biphasic Loefflers medium overlayed with PBS and supplemented with $2 \mathrm{mg}$ of rice starch [6]. The plant extracts were dissolved or suspended in the PBS overlay, at a concentration of $500 \mu \mathrm{g} / \mathrm{ml}$, resulting in 10 different media formulations (one for each of the plant extracts). Media vials were inoculated with trophozoites of $D$. fragilis and incubated at $37^{\circ} \mathrm{C}$ under microaerophilic conditions. Cultures were examined microscopically on a daily basis for several days, for the presence or absence of motile $D$. fragilis trophozoites. Each experiment was accompanied by a negative control consisting of trophozoites inoculated into the standard Loffler's slope medium. This experiment was repeated for each of the four $D$. fragilis isolates. Upon completion of this experiment, it was found that even at $500 \mu \mathrm{g} / \mathrm{ml}$, none of these plant extracts had an inhibitory effect on $D$. fragilis growth. Motile trophozoites were still present after several days (as per negative controls).

While plant derived biomolecules show promise for the development of novel antiprotozoals, it must be remembered that the beneficial properties ascribed to plants are often attributable to a few select molecules. Usually, these molecules must be properly extracted and sufficiently concentrated to see any beneficial effects when administered. In the case of dry extracts, it can be difficult (or impossible) to administer a sufficient quantity to see any benefits at all. The plant extracts used in this study have no activity against cultured D. fragilis trophozoites at a concentration of $500 \mu \mathrm{g} / \mathrm{ml}$, which exceeds that which could be achieved in the human body. However, based on the results of this study, it cannot be concluded that the plants evaluated do not possess anti-Dientamoeba activity. Rather, it is suggested that these dry plant extracts are ineffective. This finding is important for those considering natural, non-prescription therapies for treating gastrointestinal ailments in the place of conventional medicines.

Given that T. vaginalis and D. fragilis are both trichomonads, and that berberine salts from Goldenseal [7] and Pomegranate juice [8] are active against $T$. vaginalis, it was hypothesised that dry extracts from these plants would also possess anti-Dientamoeba activity. Similarly, Histomonas meleagridis is the closest known relative of D. fragilis [9], and essential oils extracted from garlic leaves possess anti-Histomonas activity [10], while powdered garlic extracts did not eradicate $D$. fragilis. The inability of the products used in this study to eradicate $D$. fragilis may be due to differences between the extracts used. For example, in this study dry plant extracts were used, while essential oil extracts [10], and purified berberine sulphate derived from Goldenseal [7], were used in studies involving other trichomonads.

To conclude, we demonstrate that various dry plant extracts available from local health stores are ineffective at eradicating cultured $D$. fragilis, for the first time. This does not confirm that these plants do not possess molecules capable of eradicating $D$. fragilis. Rather, it is concluded that dry extracts from commercial health product suppliers are ineffective. It is suggested that different types of extracts from the plants used in this study (such as lipid or organic solvent extracts) be evaluated for anti-Dientamoeba activity in future studies.

\section{Funding}

We acknowledge the financial support of St Vincent's Hospital, Sydney for completion of this work.

\section{References}

1. Anthony JP, Fyfe L, Stewart D, McDougall GJ (2011) Differential effectiveness of berry polyphenols as anti-giardial agents. Parasitology 138: 1110-1116.

*Corresponding author: Damien Stark, School of Medical and Molecular Biosciences, University of Technology, Sydney, Broadway, Australia, Tel: +612-8382-9206; E-mail: dstark@stvincents.com.au

Received August 12, 2013; Accepted August 22, 2013; Published August 27 2013

Citation: Barratt J, Ellis J, Harkness J, Marriott D, Stark D (2013) Evaluation of the in vitro Antiprotozoal Activity of Various Dry Plant Extracts against Dientamoeba fragilis. J Infect Dis Ther 1: 111. doi:10.4172/2332-0877.1000111

Copyright: $(2013$ Barratt $\mathrm{J}$, et al. This is an open-access article distributed under the terms of the Creative Commons Attribution License, which permits unrestricted use, distribution, and reproduction in any medium, provided the original author and source are credited. 
Citation: Barratt J, Ellis J, Harkness J, Marriott D, Stark D (2013) Evaluation of the in vitro Antiprotozoal Activity of Various Dry Plant Extracts against Dientamoeba fragilis. J Infect Dis Ther 1: 111. doi:10.4172/2332-0877.1000111

2. Vital PG, Rivera WL (2011) Antimicrobial activity, cytotoxicity, and phytochemical screening of Voacanga globosa (Blanco) Merr. leaf extract (Apocynaceae). Asian Pac J Trop Med 4: 824-828.

3. Dunne RL, Dunn LA, Upcroft P, O'Donoghue PJ, Upcroft JA (2003) Drug resistance in the sexually transmitted protozoan Trichomonas vaginalis. Cell Res 13: 239-249.

4. Lalle M (2010) Giardiasis in the post genomic era: Treatment, drug resistance and novel therapeutic perspectives. Infect Disord Drug Targets 10: 283-294.

5. Stark D, Barratt J, Roberts T, Marriott D, Harkness J, et al. (2010) A review of the clinical presentation of dientamoebiasis. Am J Trop Med Hyg 82: 614-619.

6. Barratt JL, Banik GR, Harkness J, Marriott D, Ellis JT, et al. (2010) Newly defined conditions for the in vitro cultivation and cryopreservation of Dientamoeba fragilis: New techniques set to fast track molecular studies on this organism. Parasitology 137: 1867-1878.
7. Soffar SA, Metwali DM, Abdel-Aziz SS, el-Wakil HS, Saad GA (2001) Evaluation of the effect of a plant alkaloid (berberine derived from Berberis aristata) on Trichomonas vaginalis in vitro. J Egypt Soc Parasitol 31: 893-904.

8. El-Sherbini GM, Ibrahim KM, El Sherbiny ET, Abdel-Hady NM, Morsy TA (2010) Efficacy of Punica granatum extract on in-vitro and in-vivo control of Trichomonas vaginalis. J Egypt Soc Parasitol 40: 229-244.

9. Delgado-Viscogliosi P, Viscogliosi E, Gerbod D, Kulda J, Sogin ML, et al. (2000) Molecular phylogeny of parabasalids based on small subunit rRNA sequences, with emphasis on the Trichomonadinae subfamily. J Eukaryot Microbiol 47: 70-75.

10. Zenner L, Callait MP, Granier C, Chauve C (2003) In vitro effect of essential oils from Cinnamomum aromaticum, Citrus limon and Allium sativum on two intestinal flagellates of poultry, Tetratrichomonas gallinarum and Histomonas meleagridis. Parasite 10: 153-157.
Citation: Barratt J, Ellis J, Harkness J, Marriott D, Stark D (2013) Evaluation of the in vitro Antiprotozoal Activity of Various Dry Plant Extracts against Dientamoeba fragilis. J Infect Dis Ther 1: 111. doi:10.4172/2332-0877.1000111
Submit your next manuscript and get advantages of OMICS Group submissions

Unique features:

User friendly/feasible website-translation of your paper to 50 world's leading languages Audio Version of published paper

Digital articles to share and explore

Special features:

- 250 Open Access Journals

20,000 editorial team

21 days rapid review process

Quality and quick editorial, review and publication processing

- Indexing at PubMed (partial), Scopus, EBSCO, Index Copernicus and Google Scholar etc

- Sharing Option: Social Networking Enabled

- Authors, Reviewers and Editors rewarded with online Scientific Credits

- Better discount for your subsequent articles

Submit your manuscript at: http://www.omicsonline.org/submission/ 